\title{
Segmental Zoster Paresis of the Right Shoulder
}

\author{
Michito Namekawa ${ }^{1}$, Tomoaki Kameda ${ }^{1}$, Ayako Kumabe ${ }^{2}$ and Junichi Mise ${ }^{2}$
}

Key words: herpes zoster, paresis

(Intern Med 52: 2839, 2013)

(DOI: 10.2169/internalmedicine.52.1231)

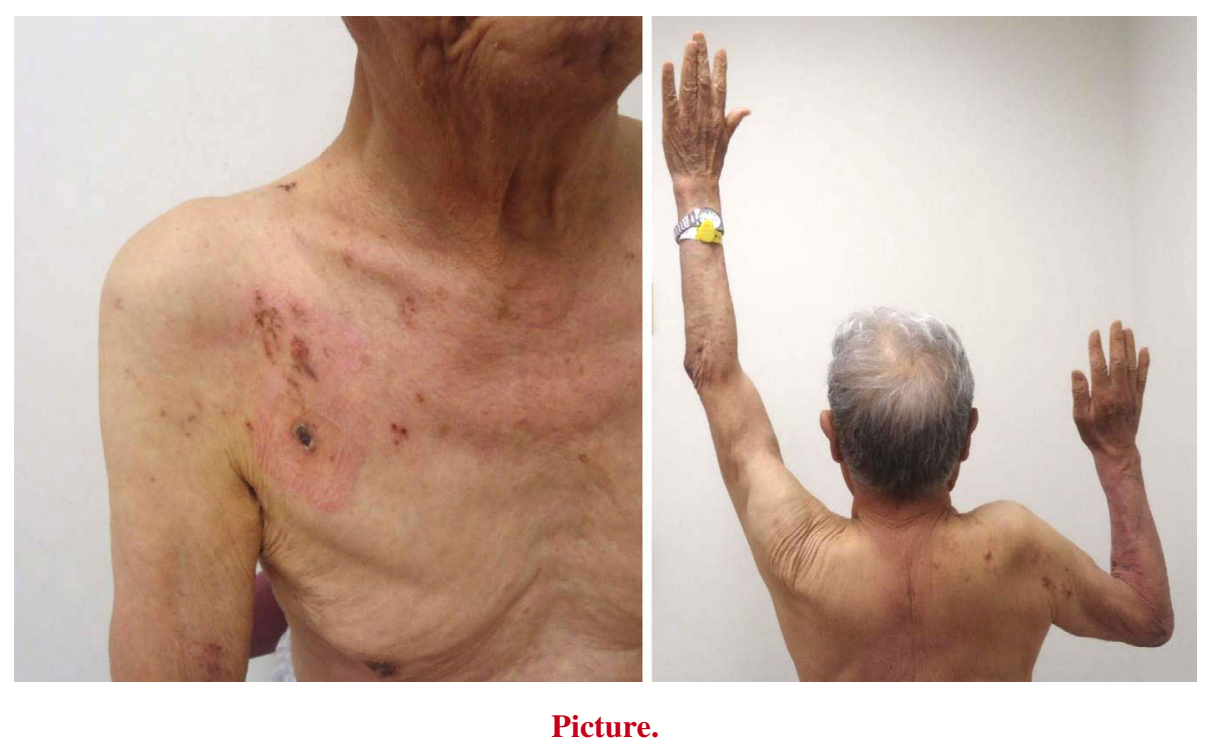

An 88-year-old man with a history of polymyalgia rheumatica that had been treated with oral prednisolone $(5 \mathrm{mg}$ per day) for five years developed a rash involving the right C3-5 dermatome. He was diagnosed as having herpes zoster, and oral valaciclovir was prescribed. Two days later, the patient developed paresis in the right shoulder (Picture). A prompt diagnosis made it possible to initiate treatment immediately with intravenous acyclovir and methylprednisolone. The paresis has gradually improved.

Segmental zoster paresis is a relatively rare complication (occurring in $3 \%$ to $5 \%$ of patients with herpes zoster) characterized by focal motor paresis in the same segment in which the skin eruptions occur (1). Proximal dominant monoparesis usually occurs within a few weeks of the onset of the rash, although it can precede the development of skin eruptions. An older age at onset is a risk factor for both manifestations associated with the incidence and severity of this disorder $(1,2)$.

The authors state that they have no Conflict of Interest (COI).

\section{References}

1. Kawajiri S, Tani M, Noda K, Fujishima K, Hattori N, Okuma Y. Segmental zoster paresis of limbs: report of three cases and review of literature. Neurologist 13: 313-317, 2007.

2. Mondelli M, Romano C, Rossi S, Cioni R. Herpes zoster of the head and limbs: Electroneuromyographic and clinical findings in 158 consecutive cases. Arch Phys Med Rehabil 83: 1215-1221, 2002.

\footnotetext{
${ }^{1}$ Department of Neurology, Jichi Medical University, Japan and ${ }^{2}$ Division of General Medicine, Center for Community Medicine, Jichi Medical University, Japan

Received for publication June 24, 2013; Accepted for publication August 9, 2013

Correspondence to Dr. Michito Namekawa, mnamekaw@jichi.ac.jp

(C) 2013 The Japanese Society of Internal Medicine Journal Website: http://www.naika.or.jp/imonline/index.html
} 